\title{
OPERATOR PADA RUANG FUNGSI TERINTEGRAL DUNFORD
}

\author{
Solikhin $^{1}$, Y.D. Sumanto ${ }^{2}$, Susilo Hariyanto ${ }^{3}$, Abdul Aziz ${ }^{4}$ \\ 1,2,3,4 Departemen Matematika, Fakultas Sains dan Matematika Universitas Diponegoro \\ Jl. Prof. Soedarto, S.H. Tembalang, Semarang, Indonesia, 50275 \\ Email: ${ }^{1}$ solikhin@live.undip.ac.id
}

\begin{abstract}
An integral Dunford and an operator on Dunford integrable functional space have discussed in this article. The results were shown that the Dunford integrable functional space was a linear function. For every Dunford integrable function on a closed interval, there is an operator that is linear bounded and weak compact operator, whereas the its adjoin operator is also linear bounded and weak compact. An operator is weak compact if and only if its adjoin operator is weak compact. Furthermore, the norm of this operator was equal to the norm of its adjoin operator.
\end{abstract}

Kata kunci: Dunford Integral, Linear Bounded Operator, Weak Compact Operator

\begin{abstract}
Abstrak. Pada artikel ini dibahas tentang integral Dunford dan operator pada ruang fungsi terintegral Dunford. Diperoleh hasil bahwa ruang fungsi yang terintegral Dunford merupakan ruang linear. Untuk setiap fungsi yang terintegral Dunford pada suatu interval tertutup, terdapat suatu operator yang bersifat linear terbatas dan operator kompak lemah, sedangkan operator adjoint-nya juga merupakan operator linear terbatas dan kompak lemah. Suatu operator bersifat kompak lemah jika dan hanya jika operator adjoint-nya kompak lemah. Lebih lanjut, didapatkan bahwa norm operator tersebut sama dengan norm operator adjoin-nya.
\end{abstract}

Kata kunci: Integral Dunford, Operator Linear Terbatas, Operator Kompak Lemah

\section{PENDAHULUAN}

Salah satu kajian pokok dalam bidang analisa matematika adalah teori integral disamping operator [1,2]. Dalam teori integral dikenal dua proses pengintegralan, yaitu secara deskriptif dan secara konstruktif. Integral deskriptif didefinisikan sebagai anti-derifatif (anti turunan), konsekuensi dari type integral ini bahwa fungsi-fungsi yang mempunyai turunan dapat diitegralkan. Contoh integral type deskriptif adalah integral Newton [3]. Sedangkan integral konstruktif didefinisikan secara konstruktif, artinya dibangun berdasarkan partisi. Integral ini salah satunya dibangun berdasarkan partisi yang dikenal sebagai integral tipe Rieman. Seperti integral Riemann, integral McShane, integral Henstock dan lain sebagainya [3, 4].

Integral Lebesgue didefinisikan berdasarkan fungsi sederhana pada sebarang himpunan terukur $E$. Integral Lebesgue ini ekuivalen dengan integral McShane [4]. Sedangkan integral McShane ekuivalen dengan integral Henstock Mutlak [3]. Oleh karena itu, integral Lebesgue ekuivalen dengan integral Henstock Mutlak. 
Integral Dunford didefinisikan sebagai fungsi terukur lemah $f$ dari interval tertutup $I$ ke ruang Banach $X(f: I \rightarrow X)$ sedemikian sehingga untuk setiap $x^{*} \in X^{*}$ ( $X^{*}$ adalah ruang dual $X$ ) fungsi bernilai real $x^{*} f: I \rightarrow R$ terintegral Lebesgue [5]. Jaminan untuk integral ini adalah Lemma Dunford [5]. Kemudian intergral Dunford diperluas ke dalam integral Henstock, yaitu fungsi bernilai real $x^{*} f$-nya diperumum dari integral Lebesgue menjadi integral Henstock. Integral ini dikenal sebagai integral Henstock-Dunford [6].

Kajian integral Henstock-Dunford pada ruang dimensi satu $R$ telah digeneralisasi ke dalam ruang Euclide $R^{n}$ [7]. Kajian integral Henstock-Dunford pada $R$ sejauh ini sebatas sifat-sifat sederhana, Teorema Perluasan Harnack dan Teorema kekonvergenan [6]. Kajian lebih lanjut dibahas perluasan Harnack dan sifat Cauchy dalam ruang Euclide $R^{n}$ [8], dan beberapa sifat-sifat small Riemann sumsnya yaitu locally, globally, functionally, dan essentially small Riemann sumsnya $[9,10,11]$. Kemudian dikaji juga tentang sifat fungsi primitifnya terkait dengan sifat fungsi kontinu mutlak, fungsi kontinu mutlak kuat, dan generalisasinya, serta kaitannya sifat fungsi bervariasi terbatas, bervariasi terbatas kuat, dan generalisasinya $[12,13]$. Kajian selanjutnya terkait integral Henstock-Dunford pada $[a, b]$ adalah kekonvergenan barisan fungsi terintegral Henstock-Dunford pada $[a, b]$, bahwa untuk menjamin fungsi $f$ terintegral Henstock-Dunford dan limit barisan sama dengan nilai fungsinya maka barisan fungsi yang terintegral Henstock-Dunford harus konvergen seragam atau konvergen lemah dan monoton lemah serta limitnya ada atau barisan fungsinya konvergen lemah dan terbatas [14]. Kemudian dibahas juga posisi integral Henstock-Dunford terhadap integral Henstock-Bochner. Diperoleh bahwa setiap fungsi yang terintegral Henstock-Bochner maka fungsi tersebut juga terintegral Henstock-Dunford tetapi sebaliknya belum tentu berlaku, sedangkan integral Henstock-Dunford ekuivalen dengan integral Henstock Lemah [15].

Berdasarkan hasil kajian terkait integral Dunford dan integral Henstock-Dunford penulis akan mengkombinasikan kajian teori integral dan teori operatornya. Khususnya akan ditinjau operator yang digunakan untuk membangun integral Dunford. Kemudian dikaji beberapa sifat dari operator yang dikontruksinya.

\section{FUNGSI TERUKUR LEMAH}

Diberikan fungsi bernilai Banach pada interval tertutup $[a, b]$. Berikut ini didefinisikan fungsi terukur bernilai Banach dan fungsi terukur lemah beserta teorema yang terkait.

Definisi 2.1 Fungsi $f:[a, b] \rightarrow X$ dikatakan sederhana jika ada himpunan terukur $A_{i} \subset[a, b], i=1,2, \ldots, n$ sehingga $A_{i} \cap A_{j}=\varnothing$, untuk setiap $i \neq j$

dan $[a, b]=\bigcup_{i=1}^{n} A_{i}$, dengan $f(x)=y_{i} \in X$ untuk $x \in A_{i}, i=1,2, \ldots, n$, yaitu fungsi $f$ adalah fungsi konstan pada himpunan terukur $A_{i}$.

Himpunan atau koleksi semua fungsi sederhana pada $[a, b]$ dinotasikan dengan $\mathfrak{J}(\mu, X)=\mathfrak{J}$. Jelas bahwa $\mathfrak{J}$ merupakan ruang linear (ruang vektor). Jika $f$ adalah fungsi sederhana maka $\|f\|_{X}:[a, b] \rightarrow \mathbb{R}$ juga merupakan fungsi sederhana. Berdasarkan fungsi sederhana, dapat didefinisikan fungsi terukur sebagai berikut. 
Definisi 2.2 Fungsi $f:[a, b] \rightarrow X$ dikatakan terukur jika ada barisan fungsi sederhana $\left(f_{n}\right), f_{n} \in \mathcal{J}, n \in \mathbb{N}$ sehingga

$$
\lim _{n \rightarrow \infty}\left\|f_{n}(t)-f(t)\right\|_{X}=0
$$

untuk setiap $t \in[a, b]$.

Berdasarkan Definisi fungsi terukur, jika $f$ fungsi sederhana pada $[a, b]$ maka $f$ merupakan fungsi terukur pada $[a, b]$. Selanjutnya jika fungsi $f:[a, b] \rightarrow X$ terukur maka fungsi bernilai real $\|f\|_{X}:[a, b] \rightarrow \mathbb{R}$ juga merupakan fungsi terukur.

Teorema 2.3 Jika $f:[a, b] \rightarrow X$ fungsi terukur maka fungsi real $\|f\|_{X}:[a, b] \rightarrow R$ fungsi terukur.

Bukti: Karena $f:[a, b] \rightarrow X$ fungsi terukur, maka ada barisan fungsi sederhana $\left(f_{n}\right), f_{n} \in \mathcal{J}, n \in \mathbb{N}$ sehingga

$$
\lim _{n \rightarrow \infty}\left\|f_{n}(t)-f(t)\right\|_{X}=0
$$

untuk setiap $t \in[a, b]$. Karena $f_{n}$ fungsi sederhana untuk setiap $n \in \mathbb{N}$, maka $\left\|f_{n}\right\|_{X}$ juga merupakan fungsi sederhana untuk setiap $n \in \mathbb{N}$. Oleh karena itu $f_{n}$ fungsi terukur, sehingga

$$
\left\|f_{n}(t)\right\|_{X}-\|f(t)\|_{X} \mid \leq\left\|f_{n}(t)-f(t)\right\|_{X},
$$

untuk setiap $t \in[a, b]$. Hal ini berarti bahwa $\lim _{n \rightarrow \infty}\left\|f_{n}(t)\right\|_{X}=\|f(t)\|_{X}$, yaitu $\|f\|_{X}$ terukur.

Selanjutnya diberikan definisi mengenai fungsi terukur lemah.

Definisi 2.4 Fungsi $f:[a, b] \rightarrow X$ dikatakan terukur lemah jika untuk setiap $x^{*} \in X^{*}$ fungsi real $x^{*}(f):[a, b] \rightarrow R$ terukur.

Menrut Definisi 2.4 dan Definisi 2.2 maka dapat diperoleh bahwa setiap fungsi terukur merupakan fungsi terukur lemah.

Teorema 2.5 Jika $f:[a, b] \rightarrow X$ terukur, maka $f:[a, b] \rightarrow X$ terukur lemah.

Bukti: Karena $f:[a, b] \rightarrow X$ terukur maka ada barisan fungsi sederhana $\left(f_{n}\right), f_{n} \in \mathcal{J}, n \in \mathbb{N}$ sehingga

$$
\lim _{n \rightarrow \infty}\left\|f_{n}(t)-f(t)\right\|_{X}=0
$$

untuk setiap $t \in[a, b]$. Diambil sebarang $x^{*} \in X^{*}$, maka berlaku

$$
\left|x^{*}\left(f_{n}(t)-f(t)\right)\right| \leq\left\|x^{*}\right\|_{X}\left\|f_{n}(t)-f(t)\right\|_{X}
$$

Karena $\lim _{n \rightarrow \infty}\left\|f_{n}(t)-f(t)\right\|_{X}=0$, maka $\lim _{n \rightarrow \infty}\left|x^{*}\left(f_{n}(t)-f(t)\right)\right|=0$. Jadi, ada barisan fungsi sederhana $\left(f_{n}\right), f_{n} \in \mathcal{J}, n \in \mathbb{N}$ sehingga 


$$
\lim _{n \rightarrow \infty}\left|x^{*}\left(f_{n}(t)-f(t)\right)\right|=0,
$$

untuk setiap $t \in[a, b]$. Hal ini berarti $x^{*}(f):[a, b] \rightarrow R$ terukur untuk setiap $x^{*} \in X^{*}$. Jadi, $f:[a, b] \rightarrow X$ terukur lemah.

Melalui fungsi terukur lemah akan dikontruksi lemma yang akan menjamin eksistensi dari integral Dunford.

Lemma 2.6 (Dunford) Jika fungsi $f:[a, b] \rightarrow X$ terukur lemah dan untuk setiap $x^{*} \in X^{*}$ fungsi bernilai real $x^{*}(f):[a, b] \rightarrow R$ terintegral Lebesque, yaitu $x^{*}(f) \in L_{1}$, maka untuk setiap himpunan terukur $A \subset[a, b]$ terdapat tunggal $x_{(f, A)}^{* *} \in X^{* *}$ sehingga

$$
x_{(f, A)}^{* *}\left(x^{*}\right)=\int_{A} x^{*}(f),
$$

untuk setiap $x^{*} \in X^{*}$.

Bukti: Diambil sebarang himpunan terukur $A \subset[a, b]$, maka untuk setiap $x^{*} \in X^{*}$ diperoleh

$$
\int_{A} x^{*} f=\int_{[a, b]} x^{*} f \chi_{A}
$$

Didefinisikan fungsi $T_{A}: X^{*} \rightarrow L_{1}$, fungsi dari dual ruang Banach $X$ ke ruang fungsi terintegral Lebesgue oleh

$$
T_{A}\left(x^{*}\right)=x^{*} f \chi_{A},
$$

untuk setiap $x^{*} \in X^{*}$. Selanjutnya didefinisikan fungsi $F_{A}: X^{*} \rightarrow R$ oleh,

$$
F_{A}\left(x^{*}\right)=\int_{A} x^{*} f=\int_{[a, b]} x^{*} f \chi_{A} .
$$

Diperoleh bahwa $F_{A}$ merupakan fungsional linier pada $X^{*}$, yaitu untuk sebarang $x^{*}, y^{*} \in X^{*}$ dan sebarang skalar $c \in R$ berlaku

$$
\begin{gathered}
F_{A}\left(x^{*}+y^{*}\right)=\int_{A}\left(x^{*}+y^{*}\right) f=\int_{A} x^{*} f+\int_{A} y^{*} f \\
=F_{A}\left(x^{*}\right)+F_{A}\left(y^{*}\right), \\
F_{A}\left(c x^{*}\right)=\int_{A}\left(c x^{*}\right) f=c \int_{A} x^{*} f=c F_{A}\left(x^{*}\right) .
\end{gathered}
$$

Misalkan untuk sebarang barisan $\left\{x_{n}^{*}\right\} \subset X^{*}$ yang konvergen ke $x^{*} \in X^{*}$ maka dapat ditunjukkan bahwa barisan $\left\{T_{A}\left(x_{n}^{*}\right)\right\}$ akan konvergen ke $g \in L_{1}$, yaitu

$$
\lim _{n \rightarrow \infty} \int_{A}\left|x_{n}^{*} f-g\right|=0 \text {. }
$$

Menurut Teorema Riez terdapat subbarisan $\left\{x_{n_{k}}^{*}\right\}, k \in \mathbb{N}$ dari $\left\{x_{n}^{*}\right\}$ sedemikian sehingga

$$
x_{n_{k}}^{*}\left(f(x) \chi_{A}(x)\right) \rightarrow g(x), k \rightarrow \infty
$$

untuk setiap $x \in[a, b]$. Oleh karena $x_{n}^{*}\left(f(x) \chi_{A}(x)\right) \rightarrow x^{*}\left(f(x) \chi_{A}(x)\right), n \rightarrow \infty$ untuk setiap $x \in[a, b]$. Hal ini berarti bahwa $g(x)=x^{*}\left(f(x) \chi_{A}(x)\right)$ untuk setiap $x \in[a, b]$ dan 
$x^{*}\left(f \chi_{A}\right) \in L_{1}$. Dengan kata lain bahwa $T_{A}: X^{*} \rightarrow L_{1}$ tertutup. Menurut Teorema Graph Tertutup Banach (Banach closed graph theorem) maka operator $T_{A}$ terbatas. Dengan demikian

$$
\begin{aligned}
\left|F_{A}\left(x^{*}\right)\right| & =\left|\int_{A} x^{*} f\right| \leq \int_{A}\left|x^{*} f\right|=\int_{A}\left|T_{A}\left(x^{*}\right)\right| \\
& =\left\|T_{A}\left(x^{*}\right)\right\|_{L_{1}} \leq\left\|T_{A}\right\|\left\|x^{*}\right\| .
\end{aligned}
$$

Jadi,

$$
\left|\int_{A} x^{*} f\right| \leq\left\|T_{A}\right\|\left\|x^{*}\right\| .
$$

Oleh karena itu, $\int_{A} x^{*} f$ merupakan fungsional linear kontinu pada $X^{*}$ yang pendefisiannya oleh $x_{(f, A)}^{* *} \in X^{* *}$

\section{INTEGRAL DUNFORD}

Berdasarkan Lemma Dunford, maka dapat didefinisikan integral Dunford sebagai berikut.

Definisi 3.1 Fungsi $f:[a, b] \rightarrow X$ dikatakan terintegral Dunford pada $[a, b]$, jika untuk setiap $x^{*} \in X^{*}$ fungsi real $x^{*}(f):[a, b] \rightarrow \mathbb{R}$ terintegral Lebesque dan untuk setiap himpunan terukur $A \subset[a, b]$ terdapat $x_{(f, A)}^{* *} \in X^{* *}$ sehingga

$$
x_{(f, A)}^{* *}\left(x^{*}\right)=(L) \int_{A} x^{*}(f)
$$

untuk setiap $x^{*} \in X^{*}$.

Nilai integral Dunford $(D) \int_{A} f$, fungsi $f$ atas himpunan terukur $A \subset[a, b]$ diberikan oleh $x_{(f, A)}^{* *} \in X^{* *}$, yaitu

$$
x_{(f, A)}^{* *}=(D) \int_{A} f
$$

di mana $x_{(f, A)}^{* *}\left(x^{*}\right)=(L) \int_{A} x^{*}(f)$, untuk setiap $x^{*} \in X^{*}$. Himpunan semua fungsi $f$ terintegral Dunford pada $[a, b]$ ditulis $f \in D[a, b]$. Jika $f:[a, b] \rightarrow X$ dan $f \in D[a, b]$ berarti bahwa $x^{*}(f) \in L_{1}$ untuk setiap $x^{*} \in X^{*}$.

Teorema eksistensi ketunggalan nilai suatu integral Dunford.

Teorema 3.2 Jika $f \in D[a, b]$, maka untuk setiap himpunan terukur $A \subset[a, b]$ vektor $x_{(f, A)}^{* *} \in X^{* *}$ tunggal. 
Bukti: Diberikan sebarang himpunan terukur $A \subset[a, b]$. Andaikan terdapat vektor $x_{1(f, A)}^{* *} \in X^{* *}$ dan $x_{2(f, A)}^{* *} \in X^{* *}$ maka

$$
\begin{aligned}
& x_{1(f, A)}^{* *}\left(x^{*}\right)=(L) \int_{A} x^{*}(f) \text { dan } \\
& x_{2(f, A)}^{* *}\left(x^{*}\right)=(L) \int_{A} x^{*}(f) .
\end{aligned}
$$

Oleh karena itu

$$
\begin{aligned}
& x_{1(f, A)}^{* *}\left(x^{*}\right)-x_{2(f, A)}^{* *}\left(x^{*}\right) \\
& =(L) \int_{A} x^{*}(f)-(L) \int_{A} x^{*}(f)=0, \forall x^{*} \in X^{*} .
\end{aligned}
$$

Jadi $x_{1(f, A)}^{* *}=x_{2(f, A)}^{* *}$.

Teorema 3.3 Jika fungsi $f$ terintegral Dunford pada $[a, b]$, maka $f$ terintegral Dunford pada A untuk setiap himpunan terukur $A \subset[a, b]$.

Bukti: Jelas menurut Definisi 3.2.1.

Contoh sederhana suatu fungsi yang terintegral Dunford pada $[a, b]$ adalah fungsi konstan.

Contoh 3.4 Diberikan fungsi konstan $f(x)=c$ untuk setiap $x \in[a, b]$, maka $f$ terintegral Dunford pada $[a, b]$.

Teorema 3.5 Fungsi $f$ terintegral Dunford pada $[a, b]$ jika dan hanya jika untuk setiap $x^{*} \in X^{*}$ fungsi real $x^{*} f$ terintegral Lebesgue pada $[a, b]$.

Bukti: Diketahui fungsi $f$ terintegral Dunford pada $[a, b]$ maka untuk setiap $x^{*} \in X^{*}$ fungsi real $x^{*} f$ terintegral Lebesgue pada $[a, b]$.

Sebaliknya jika fungsi real $x^{*} f$ terintegral Lebesgue pada $[a, b]$ maka $f$ terintegral Dunford pada $[a, b]$.

Contoh 3.6 Jika $f$ terintegral Lebesgue pada $[a, b]$, maka $f$ terintegral Dunford pada $[a, b]$

Contoh 3.7 Jika $f$ terintegral Riemann pada $[a, b]$, maka $f$ terintegral Dunford pada $[a, b]$. Hal ini karena setiap fungsi terintegral Riemann maka terintegral Lebesgue. Selanjutnya jika fungsi $f$ terintegral Lebesgue maka untuk setiap $x^{*} \in X^{*}$ fungsi bernilai real $x^{*} f$ juga terintegral Lebesgue. Oleh karena itu fungsi $f$ terintegral Dunford.

Koleksi semua fungsi $f$ yang terintegral Dunford pada $[a, b]$, dinotasikan $D[a, b]$ merupakan ruang linear.

Teorema 3.8 $D[a, b]$ adalah ruang linear. 
Bukti: Diambil sebarang $f, g \in D[a, b]$ dan sebarang $c \in R$. Ditunjukkan bahwa $f+g \in D[a, b]$ dan $c f \in D[a, b]$. Karena $f, g \in D[a, b]$ maka untuk setiap $x^{*} \in X^{*}$ fungsi real $x^{*} f$ dan $x^{*} g$ terintegral Lebesgue pada $[a, b]$. Oleh karena itu untuk setiap $x^{*} \in X^{*}$ $x^{*}(f+g)=x^{*} f+x^{*} g$ terintegral Lebesgue pada $[a, b]$. Jadi, fungsi $f+g$ terintegral Dunford pada $[a, b]$, yaitu $f+g \in D[a, b]$.

Karena $f \in D[a, b]$ maka untuk setiap $x^{*} \in X^{*}$ fungsi real $x^{*} f$ terintegral Lebesgue pada $[a, b]$. Oleh karena itu untuk sebarang skalar $c \in R$ dan untuk setiap $x^{*} \in X^{*} \quad$ fungsi $x^{*}(c f)=c x^{*} f$ terintegral Lebesgue pada $[a, b]$. Jadi, fungsi $c f$ terintegral Dunford pada $[a, b]$, yaitu $c f \in D[a, b]$.

Jadi, $c f \in D[a, b]$ ruang linier.

\section{OPERATOR PADA RUANG FUNGSI TERINTEGRAL DUNFORD}

Berdasarkan bukti dari Lemma Dunford, dapat dikontruksi operator pada ruang fungsi terintegral Dunford. Diketahui $L_{1}$ adalah ruang fungsi terintegral Lebesgue pada $[a, b], X$ ruang Banach, dan $X^{*}$ dual dari $X$. Didefinisikan operator $T: X^{*} \rightarrow L_{1}$ oleh

$$
T\left(x^{*}\right)=x^{*}(f)
$$

untuk setiap $x^{*} \in X^{*}$. Operator $T$ seperti pada definisi tersebut merupakan operator linear terbatas atau linear kontinu.

Teorema 4.1 Operator $T$ merupakan operator linear terbatas.

Bukti: Diambil sebarang $x^{*}, y^{*} \in X^{*}$ dan sebarang $c \in R$ diperoleh

$$
\begin{aligned}
T\left(x^{*}+y^{*}\right) & =\left(x^{*}+y^{*}\right)(f) \\
& =x^{*}(f)+y^{*}(f) \\
& =T\left(x^{*}\right)+T\left(y^{*}\right),
\end{aligned}
$$

dan

$$
T\left(c x^{*}\right)=\left(c x^{*}\right)(f)=c x^{*}(f)=c T\left(x^{*}\right) .
$$

Jadi operator $T$ linear. Lebih lanjut menurut Teorema Banach Graf Tertutup, operator $T$ terbatas.

Lemma 4.2 Dual dari $L_{1}$ adalah $L_{\infty}$, yaitu $L_{1}^{*}=L_{\infty}$.

Bukti: Untuk setiap $y=\left\{y_{n}\right\} \in L_{\infty}$ dibentuk fungsional $F_{y}$ pada $L_{1}$ dengan rumus

$$
F_{y}(x)=\sum_{n=1}^{\infty} x_{n} y_{n}
$$

Diperoleh bahwa $F_{y}$ linear, yaitu untuk sebarang $x=\left\{x_{n}\right\}, z=\left\{z_{n}\right\} \in L_{1}$ dan sebarang skalar $c \in R$ berlaku 


$$
\begin{aligned}
F_{y}(x+z) & =\sum_{n=1}^{\infty}\left(x_{n}+z_{n}\right) y_{n} \\
& =\sum_{n=1}^{\infty}\left(x_{n}\right) y_{n}+\sum_{n=1}^{\infty}\left(z_{n}\right) y_{n} \\
& =F_{y}(x)+F_{y}(z),
\end{aligned}
$$

dan

$$
\begin{aligned}
F_{y}(c x) & =\sum_{n=1}^{\infty}\left(c x_{n}\right) y_{n}=c \sum_{n=1}^{\infty}\left(x_{n}\right) y_{n} \\
& =c F_{y}(x) .
\end{aligned}
$$

Diperoleh juga bahwa $F_{y}$ kontinu, yaitu

Untuk setiap $x=\left\{x_{n}\right\} \in L_{1}$ berlaku

$$
\left|F_{y}(x)\right|=\left|\sum_{n=1}^{\infty} x_{n} y_{n}\right| \leq\|x\|_{1}\|y\|_{\infty} .
$$

Jadi setiap $y=\left\{y_{n}\right\} \in L_{\infty}$ menentukan dengan tunggal fungsional linear kontinu $F_{y}$ pada $L_{1}$, atau $L_{\infty} \subset L_{1}^{*}$. Sebaliknya, diambil sebarang fungsional linear kontinu $F$ pada $L_{1}$. Untuk setiap $x=\left\{x_{n}\right\} \in L_{1}$ dapat direpresentasikan oleh

$$
x=\sum_{n=1}^{\infty} x_{n} e_{n},
$$

dengan $e_{n}=\{0, \ldots, \underset{\mathrm{ke} n}{1}, 0, \ldots, 0\}$. Karena $F$ linear, maka diperoleh

$$
F(x)=F\left(\sum_{n=1}^{\infty} x_{n} e_{n}\right)=\sum_{n=1}^{\infty} x_{n} F\left(e_{n}\right) .
$$

Hal ini berarti bahwa $F(x)$ merupakan kombinasi linear dari barisan bilangan $\left\{F\left(e_{n}\right)\right\}$ atau fungsional linear kontinu $F$ bergantung pada barisan bilangan $\left\{F\left(e_{n}\right)\right\}$.

Selanjutnya karena $F$ kontinu, maka $|F(x)|$ terbatas, yaitu $|F(x)|<\infty$. Menurut Ketaksamaan Cauchy-Schwartz, diperoleh

$$
\begin{aligned}
|F(x)| & =\left|F\left(\sum_{n=1}^{\infty} x_{n} e_{n}\right)\right|=\left|\sum_{n=1}^{\infty} x_{n}\left(F\left(e_{n}\right)\right)\right| \\
& \leq\|x\|_{L_{1}} \sup _{n \geq 1}\left|F\left(e_{n}\right)\right| .
\end{aligned}
$$

Supaya $F(x)$ terbatas, maka haruslah $\sup _{n \geq 1}\left|F\left(e_{n}\right)\right|<\infty$. Hal ini berarti bahwa $y=\left\{T\left(e_{n}\right)\right\} \in L_{\infty}$. Jadi, setiap fungsional linear kontinu $F$ pada $L_{1}$ menentukan dengan tunggal vektor $y=\left\{T\left(e_{n}\right)\right\} \in L_{\infty}$, yaitu $L_{1}^{*} \subset L_{\infty}$.

Jadi, karena $L_{\infty} \subset L_{1}^{*}$ dan $L_{1}^{*} \subset L_{\infty}$, maka $L_{1}^{*}=L_{\infty}$. $\square$

Misalkan $X^{* *}$ dual kedua dari $X$. Didefinisikan operator $T^{*}: L_{1}^{*} \rightarrow X^{* *}$ oleh 


$$
T^{*}(g)\left(x^{*}\right)=\int_{a}^{b} g T\left(x^{*}\right)=\int_{a}^{b} g x^{*}(f)
$$

untuk setiap $g \in L_{1}^{*}=L_{\infty}$. Operator $T^{*}$ disebut operator adjoint pada $L_{1}$.

Teorema 4.3 Operator adjoint $T^{*}$ merupakan operator linear terbatas dan

$$
\left\|T^{*}\right\|=\|T\| \text {. }
$$

Bukti: Operator adjoint $T^{*}$ linear, yaitu untuk sebarang $g_{1}, g_{2} \in L_{1}^{*}=L_{\infty}$ dan sebarang skalar $c_{1}, c_{2} \in R$ berlaku

$$
\begin{gathered}
T^{*}\left(c_{1} g_{1}+c_{2} g_{2}\right)\left(x^{*}\right)=\int_{a}^{b}\left(c_{1} g_{1}+c_{2} g_{2}\right) T\left(x^{*}\right) \\
=\int_{a}^{b}\left(c_{1} g_{1} T\left(x^{*}\right)+c_{2} g_{2} T\left(x^{*}\right)\right) \\
=c_{1} \int_{a}^{b}\left(g_{1} T\left(x^{*}\right)\right)+c_{2} \int_{a}^{b}\left(g_{2} T\left(x^{*}\right)\right) \\
=c_{1} T^{*}\left(g_{1}\right)\left(x^{*}\right)+c_{2} T^{*}\left(g_{2}\right)\left(x^{*}\right) .
\end{gathered}
$$

Karena $f=T^{*}(g)$ dan $\|f\| \leq\|g\|\|T\|$ maka diperoleh $\left\|T^{*}(g)\right\|=\|f\| \leq\|g\|\|T\|$.

Jadi, $\left\|T^{*}\right\| \leq\|T\|$. Untuk setiap $x_{0}^{*} \neq \theta \in X^{*}$ terdapat $g_{0} \in X^{* *}$ dengan

$$
\left\|g_{0}\right\|=1 \text { dan } g_{0}\left(T\left(x_{0}^{*}\right)\right)=\left\|T\left(x_{0}^{*}\right)\right\| \text {. }
$$

Jadi,

$$
g_{0}\left(T\left(x_{0}^{*}\right)\right)=T^{*}\left(g_{0}\right)\left(x_{0}^{*}\right) .
$$

Katakan $f_{0}=T^{*}\left(g_{0}\right)$ dan diperoleh

$$
\begin{aligned}
\left\|T x_{0}^{*}\right\| & =g_{0} T\left(x_{0}^{*}\right)=f_{0}\left(x_{0}^{*}\right) \leq\left\|f_{0}\right\|\left\|x_{0}^{*}\right\| \\
& =\left\|T^{*} g_{0}\right\|\left\|x_{0}^{*}\right\| \leq\left\|T^{*}\right\|\left\|g_{0}\right\|\left\|x_{0}^{*}\right\| .
\end{aligned}
$$

Karena $\left\|g_{0}\right\|=1$, sehingga untuk setiap $x_{0}^{*} \neq \theta \in X^{*}$ berlaku $\left\|T x_{0}^{*}\right\| \leq\left\|T^{*}\right\|\left\|x_{0}^{*}\right\|$. Jadi, $\|T\| \leq\left\|T^{*}\right\|$.

Karena $\|T\| \leq\left\|T^{*}\right\|$ dan $\left\|T^{*}\right\| \leq\|T\|$, maka $\left\|T^{*}\right\|=\|T\|$.

Teorema 4.4 Diketahui fungsi $f:[a . b] \rightarrow X$ terintegral Dunford pada $[a, b]$, maka pernyataan-pernyataan berikut ekuivalen:

1) Operator $T: X^{*} \rightarrow L_{1}$ merupakan operator kompak lemah (weakly compact).

2) Operator adjoint $T^{*}: L_{\infty} \rightarrow X^{* *}$ merupakan operator kompak lemah.

3) Himpunan $\left\{x^{*}(f) \mid x^{*} \in B\left(X^{*}\right)\right\} \subset L_{1}$ terintegral seragam, yaitu

$$
\lim _{\alpha(A) \rightarrow 0} \int_{A} x^{*}(f)=0
$$

seragam untuk setiap $x^{*} \in B\left(X^{*}\right)$. 
4) Indefinit integral Dunford $v(A)$ adalah countably additive, yaitu jika $A_{n} \subset[a, b], n \in \mathbb{N}$ himpunan terukur yang saling asing maka

$$
v\left(\bigcup_{n=1}^{\infty} A_{n}\right)=\sum_{n=1}^{\infty} v\left(A_{n}\right)
$$

di $X^{* *}$ (deret $\sum_{n=1}^{\infty} v\left(A_{n}\right)$ konvergen di $\left.X^{* *}\right)$.

Bukti: Menurut Teorema Gantmacher's, Operator $T$ kompak lemah jika dan hanya jika operator adjoint $T^{*}$ juga kompak lemah. Jadi 1) dan 2) ekuivalen. Diberikan himpunan

$$
T\left(B\left(X^{*}\right)\right)=\left\{x^{*} f \mid x^{*} \in B\left(X^{*}\right)\right\} \subset L_{1} .
$$

Karena $f$ terintegral Dunford pada $[a, b]$ maka untuk setiap $x^{*} \in X^{*}$ fungsi real $x^{*} f$ terintegral Lebesgue pada $[a, b]$, yaitu $x^{*} f \in L_{1}$ sehingga diperoleh

$$
\left\|x^{*} f\right\|_{L_{1}}=\int_{[a, b]}\left|x^{*} f\right|=\left\|T\left(x^{*}\right)\right\|_{L_{1}} \leq\|T\|<\infty
$$

untuk setiap $x^{*} \in B\left(X^{*}\right)$. Karena operator $T$ terbatas, maka himpunan $T\left(B\left(X^{*}\right)\right)$ juga terbatas. Himpunan $T\left(B\left(X^{*}\right)\right) \subset L_{1}$ adalah kompak lemah jika dan hanya jika $\lim _{\alpha(A) \rightarrow 0} \int_{A} x^{*} f$ seragam untuk setiap $x^{*} \in B\left(X^{*}\right)$. Hal ini berarti 3) ekuivalen 1). Diketahui bahwa 3) terpenuhi, maka $\lim _{\alpha(A) \rightarrow 0} \int_{A}\left|x^{*} f\right|=0$, seragam untuk setiap $x^{*} \in B\left(X^{*}\right)$. Berarti untuk setiap $\eta>0$ terdapat $\varepsilon>0$ sedemikian sehingga

$$
\left|T\left(\chi_{A}\right)\left(x^{*}\right)\right|=\left|\int_{A} x^{*}(f)\right|<\eta
$$

untuk setiap $x^{*} \in B\left(X^{*}\right)$. Jika $\alpha(A)<\varepsilon$ maka diperoleh $\left\|T\left(\chi_{A}\right)\right\| \leq \eta$. Jika $A_{n} \subset[a, b]$ untuk setiap $n \in \mathbb{N}$ himpunan terukur yang saling asing dan $A=\bigcup_{n=1}^{\infty} A_{n}$, maka

$$
\lim _{N \rightarrow \infty} \alpha\left(A-\bigcup_{n=1}^{N} A_{n}\right)=0 .
$$

Akibatnya

$$
\lim _{N \rightarrow \infty}\left\|v\left(A-\bigcup_{n=1}^{N} A_{n}\right)\right\|_{X^{* *}}=0 .
$$

Karena $A=\left(A-\bigcup_{n=1}^{N} A_{n}\right) \cup \bigcup_{n=1}^{N} A_{n}$, maka

$$
\begin{gathered}
T^{*}\left(\chi_{A}\right)=T^{*}\left(\chi_{A-\bigcup_{n=1}^{N} A_{n}}\right)+T^{*}\left(\chi_{\bigcup_{n=1}^{N} A_{n}}\right) \\
=T^{*}\left(\chi_{A-\bigcup_{n=1}^{N} A_{n}}\right)+\sum_{n=1}^{N} T^{*}\left(\chi_{A_{n}}\right) .
\end{gathered}
$$


Hal ini berarti bahwa

$$
v(A)-\sum_{n=1}^{N} v\left(A_{n}\right)=v\left(A-\bigcup_{n=1}^{N} A_{n}\right)
$$

dan

$$
\lim _{N \rightarrow \infty}\left\|v(A)-\sum_{n=1}^{N} v\left(A_{n}\right)\right\|=\lim _{N \rightarrow \infty}\left\|v\left(A-\bigcup_{n=1}^{N} A_{n}\right)\right\|=0 .
$$

Jadi, $v(A)$ countably additive.

Andaikan 3) tidak berlaku, maka terdapat $k>0$ dan barisan himpunan terukur $\left\{A_{n}\right\} \subset[a, b]$ untuk setiap $n \in \mathbb{N}$ dengan $\alpha\left(A_{n}\right) \rightarrow 0, n \rightarrow \infty$ dan

$$
\int_{A_{n}}\left|x_{n}^{*} f\right|>k
$$

untuk suatu $x_{n}^{*} \in B\left(X^{*}\right)$.

Karena himpunan terukur $A_{n}$ berukuran menuju 0, maka ada kemungkinan subbarisan dari $A_{n}$ dan asumsikan bahwa $m<n$ sehingga diperoleh

$$
\int_{A_{m}}\left|x_{n}^{*} f\right|<\frac{k}{2^{n+1}} \text {. }
$$

Katakan $E_{n}=A_{n}-\bigcup_{m<n} A_{n} ; E_{n} \subset[a, b]$ himpunan-himpunan terukur dengan $E_{n} \cap E_{l}=\varnothing, n \neq l$ dan

$$
\int_{E_{n}}\left|x_{n}^{*} f\right|=\int_{A_{n}}\left|x_{n}^{*} f\right|-\int_{m<n}\left|x_{n}^{*} f\right|>\frac{k}{2} .
$$

Jadi, terdapat $B_{n} \subset E_{n}$ himpunan terukur yang saling asing sehingga

$$
\int_{B_{n}}\left|x_{n}^{*} f\right|>\frac{k}{4}
$$

Dengan demikian $\left\|T^{*}\left(\chi_{B_{n}}\right)\right\|>\frac{k}{4}$, untuk setiap $n \in \mathbb{N}$. Jadi, deret $\sum_{n=1}^{\infty} T^{*}\left(\chi_{B_{n}}\right)=\sum_{n=1}^{\infty} v\left(B_{n}\right)$ tidak konvergen. Hal ini berarti 4) tidak memenuhi.

Jadi, 3) ekuivalen 4).

\section{KESIMPULAN}

Berdasarkan hasil pembahasan yang diuraikan dalam bentuk beberapa teorema maka dapat diambil kesimpulan bahwa koleksi semua fungsi yang terintegral Dunford merupakan ruang linear dan untuk setiap fungsi $f$ yang terintegral Dunford pada $[a, b]$, maka operator $T$ dengan formula $T\left(x^{*}\right)=x^{*}(f)$ merupakan operator linear terbatas dan operator kompak lemah. Sedangkan operator adjoint $T^{*}$, dengan rumus $T^{*}(g)\left(x^{*}\right)=\int_{a}^{b} g x^{*}(f)$ juga 
merupakan operator linear terbatas dan kompak lemah. Operator $T$ kompak lemah jika dan hanya jika operator adjoint $T^{*}$ kompak lemah. Lebih lanjut $\left\|T^{*}\right\|=\|T\|$.

\section{DAFTAR PUSTAKA}

[1] Darmawijaya, S. (2007), Pengantar Analisis Abstrak, Jurusan Matematika Fakultas MIPA Universitas Gadjah Mada, Yogyakarta.

[2] Kreyszig, E. (1989), Introductory Funtional Analysis with Applications, John Willey \& Sons, USA.

[3] Lee P.Y. (1989), Lanzhou Lectures on Henstock Integration, World Scientific, Singapore.

[4] Gordon, R.A. (1994), The Integral of lebesgue, Denjoy, Perron, and Henstock, Mathematical Society, USA.

[5] Schwabik, S., Guoju, Ye. (2005), Topics in Banach Space Integration, World Scientific, Singapore.

[6] Guoju, Ye., Tianqing, An. (2001), On Henstock-Dunford and Henstock-Pettis Integrals, IJMMS, 25(7): 467-478.

[7] Saifullah. (2003), Integral Henstock-Dunford pada Ruang Euclide $R^{n}$, Tesis, Universitas Gadjah Mada, Yogyakarta.

[8] Solikhin, (2013), Perluasan Harnack dan Sifat Cauchy Integral henstock-Dunford pada Ruang Euclide R ${ }^{\mathrm{n}}$, Jurnal Matematika, 16(1): 8-12.

[9] Solikhin, Sumanto, Khabibah. (2013), Locally dan Globally Small Riemann Sums Fungsi Terintegral Henstock-Dunford pada [a,b], Prosiding Seminar Nasional Matematika dan Pendidikan Matematika, 9 November 2013, A.8 halaman 55-64, ISBN 978-97916353-9-4.

[10] Solikhin, Sumanto, Khabibah. (2012), Functionally Small Riemann Sums Fungsi Terintegral Henstock-Dunford pada [a,b], Jurnal Sains dan Matematika, 20(3): 58-63.

[11] Solikhin, Sumanto, Siti Khabibah. (2014), Essesntially Small Riemann Sums Fungsi Terintegral Henstock-Dunford pada [a,b], Jurnal Matematika, 17(1): 55-61.

[12] Solikhin, Sumanto, Abdul Aziz. (2014), Fungsi Primitif Integral Henstock-Dunford pada $[a, b]$, Laporan Penelitian, Jurusan Matematika FSM Undip, Semarang.

[13] Solikhin. (2017), Karakteristik Fungsi Primitive Integral Henstock-Dunford pada [a,b], Prosiding Seminar Nasional Matematika dan Pendidikan Matematika, 25 Februari 2017, hal 107-115, ISBN 978-602-6100-0-0.

[14] Solikhin, Heru Tjahjana, Solichin Zaki. (2016), Kekonvergenan Barisan Fungsi Terintegral Henstock-Dunford pada [a,b], Jurnal Matematika, 19(1): 29 - 39.

[15] Solikhin, Heru Tjahjana, Solichin Zaki. (2016), Posisi Integral Henstock-Dunford dan Integral Henstock-Bochner pada [a,b], Prosiding Seminar Nasional Matematika dan Pendidikan Matematika, 5 November 2016, hal MA 85 - MA 92, ISBN 978-60273403-1-2. 